\title{
Designing a Game to Help Higher Education Students Develop Their Note-Taking Skills
}

\author{
Thaleia Deniozou \\ Department of Arts and \\ Humanities \\ Brunel University London \\ London, UK \\ thaleia.deniozou@brunel.ac.uk
}

\author{
Mariza Dima \\ Department of Arts and \\ Humanities \\ Brunel University London \\ London, UK \\ mariza.dima@brunel.ac.uk
}

\author{
Chris Cox \\ Department of Arts and \\ Humanities \\ Brunel University London \\ London, UK \\ chris.cox@brunel.ac.uk
}

\begin{abstract}
Taking effective notes is an important skill in academic and professional settings and one that is cultivated primarily in Higher Education (HE). However, students often find it difficult to effectively record important information in their notes [37], while it has been suggested that they often record less than $50 \%$ of the key information of a lecture [15].

Games can be a powerful way to help students learn [30]. Yet, to date, there is scarce empirical research on games specifically designed to help HE students develop note-taking skills where the design has been directly informed by note-taking learning theories. This study applies such theories in the design of the mechanics for an educational game for note-taking, entitled Investigate: Tudors, and evaluates their effectiveness and engaging potential.

Results from qualitative evaluations with HE students showed that the game was a successful tool to help them develop notetaking skills. This article discusses the game design approach and the evaluation results, and contributes with effective strategies for designing serious games for note-taking.
\end{abstract}

\section{CCS CONCEPTS}

- Applied computing $\sim$ Computers in other domains $\sim$ Personal computers and PC applications $\sim$ Computer games • Applied computing $\sim$ Education $\sim$ Interactive learning environments

\section{KEYWORDS}

Game-based Learning; Serious Games; Video Games; Learning in Higher Education; Note-taking Skills; Learning Strategies

Permission to make digital or hard copies of all or part of this work for personal or classroom use is granted without fee provided that copies are not made or distributed for profit or commercial advantage and that copies bear this notice and the full citation on the first page. Copyrights for components of this work owned by others than the author(s) must be honored. Abstracting with credit is permitted. To copy otherwise, or republish, to post on servers or to redistribute to lists, requires prior specific permission and/or a fee. Request permissions from Permissions@acm.org.

CHI PLAY'20, November 2-4, 2020, Virtual Event, Canada

(C) 2020 Copyright is held by the owner/author(s). Publication rights licensed to ACM.

ACM ISBN 978-1-4503-8074-4/20/11..\$15.00

https://doi.org/10.1145/3410404.3414230

\section{Introduction}

Taking notes is an integral part of academic study. Developing note-taking skills is therefore important for students of Higher Education (HE), since effective note-taking can increase recall [8], facilitate academic achievement [37] and help retention [28] and comprehension [50]. Taking notes is based on the ability to effectively listen and organise concepts in a lecture format [15] and allows record keeping of key information, which helps understanding, revision and ultimately learning. Notetaking is a transferable skill which facilitates the development of critical thinking as a key lifelong learning skill, using the ability to prioritise and summarise information while documenting it in meaningful ways. Taking effective notes is useful in academic and professional settings and can help decision-making and problem solving [28].

Despite the importance of note-taking however, many students are unaware of its benefits and the importance of cultivating their note-taking skills over the course of their education [28]. Note-taking is not necessarily a skill that students have upon arriving at University but an acquired skill $[59,28]$. Students often appear to be incomplete note takers who find it difficult to effectively record important information in their notes [37], while it has been suggested that students often record less than $50 \%$ of the key information of a lecture [15]. One method found to enhance note-taking is providing hand-outs in order to highlight key information in advance and provide students a scaffold for organising concepts [65]. A balance needs to be found however, since providing full notes via hand-outs diverts students from the active act of note-taking [65] and encourages them to become passive listeners [15]. Empirical research has suggested a few other ways to assist note-taking, including orienting students towards important ideas and topics, encouraging content connections, and helping students consider how to take effective notes [28].

Aspects of note-taking and review, as they relate to student learning, have been an active area of educational research for years [15]. Older literature reviews [60,36], as well as more recent ones [28], have demonstrated that note-taking practices should be encouraged, and that interventions to assist students in the note-taking process can enhance learning [40]. Such interventions should highlight best practices. Methods to 
facilitate and support this process in various contexts are explored in literature, with studies looking at natural note-taking [14], note-taking in the digital age, exploring areas such as mobile technology implications [55], the use of wireless technologies for collaborative note-taking [58], and the use of the iPad for innovative note-taking [4]. However, there is only but scarce empirical evidence in literature on the use of gamebased learning to assist the development of note-taking skills. The study presented in this article explores practically the use of educational games for note-taking focussing on the game design approach.

\section{Game-based Learning for Skills Development}

Game-based learning (GBL) describes learning facilitated via games. Games for learning are an area of practice and research, which has grown considerably in recent years with an increasing number of empirical evidence and case studies that demonstrate their impact [11]. Educational games are often described by the term serious games (SGs), which refers to games designed primarily with a goal other than pure entertainment, such as a pedagogical one [42]. The term SG is often used in literature interchangeably with 'games for learning' [11]. De Freitas [22] supports the potential of educational games, which via utilising characteristics of computer games can create opportunities for engaging learning experiences, aiming to deliver specific learning outcomes.

Recent research on the cognitive gains and engagement potential of educational games has led to increased interest in the application of GBL for various learning frameworks. One of the most frequent learning outcomes investigated in games for learning is knowledge acquisition [18], while the most frequent subject areas games are used across are Science, Technology, Engineering and Maths (STEM) followed by Health Science and Business and Languages [11]. In contrast, there is very little evidence on the effectiveness and impact of using educational games for 21st century skills development [52] as well as transferable academic skills such as note-taking. Although games have been proven a useful tool for developing practical skills, and they promote meaningful learning via active participation, problem-solving, immediate feedback, clear goals and player control $[21,1,30,54,63]$, their effectiveness for different learning contexts remains to be investigated. According to [20], a general lack of research is evident, particularly in HE where GBL adoption is still relatively low. Schell argues that good educational games, which deliver learning while still engaging, are hard to make [53]. Designing games for specific educational purposes can be challenging since a combination of disciplines like deep understanding of game design theory, subject area expertise and a foundation in relevant learning theory is essential [10]. While there are commercial games mostly in the spy/RPG/puzzle genres, such as Clue and L.A. Noire, that either incorporate some form of note-taking into gameplay or could benefit from players taking notes, these games are not designed and developed with a primary focus on helping players take better notes. They also don't consider the learner group and subject area as their target audience nor utilise note-taking literature to inform the design process. In the case of Investigate: Tudors however, the different disciplines of game design, subject area knowledge and relevant learning theory, were brought together via the combination of the stakeholders' expertise, to design an educational game that is appropriate for developing note-taking skills.

\section{The Game Design Process}

An imperative of the design approach was to design the game mechanics based on note-taking learning theories and, therefore, build a game from the ground up. The design process started with the consideration of the learning needs of the target group of learners, the type of game that would best fit the context, and an examination of theoretical foundations, which would best support the learning objective.

\subsection{Type of Learner and Theoretical Context}

Students of HE are adult learners who present some differences from school-aged learners in their approaches and motivations to learning and studying. Although it could be argued that first-year undergraduate University students have much in common with younger learners, they have made the choice to study at University and in many cases pay fees for their experience [61]. Second and third year undergraduate University students, progressively display more characteristics of adult learners and gradually become more independent. Postgraduate students even more so, since they are usually older or could be mature students coming back to learning after a break from formal education [31]. Adult learning theory, or andragogy [39], looks into the characteristics of adult learners and their differences in relation to younger learners and describes the key premises of adult learning. According to Knowles [39], these premises are: (1) adults need to know why they need to learn something, (2) they need to be self-directed and take responsibility for their learning, (3) they have a wide variety of experiences and backgrounds and do not come from the same starting point, (4) they are motivated to learn to cope more effectively with real-life situations and (5) they are taskoriented and learn things best in the context of using them. Therefore, it becomes apparent that relevance and purpose are important factors to consider when designing learning solutions for adults, since these learners are motivated by an ability to apply skills and knowledge to address real life needs. Games are considered to be intrinsically motivational [51], but for adult learners the motivational power of games primarily comes from creating rich learning situations which can help them develop skills in a self-directed way and actively practice newly acquired competencies in a safe environment, before directly translating them to real life. As adults tend to be more practical in their learning approaches, providing them with stimulation through a game environment specifically designed for practical skills development, could trigger their intrinsic impetus and enhance their motivation to engage. GBL could prove effective in this context, via aligning the learning content and the game 
objectives, thus allowing skills to be developed incidentally as learners find solutions to progress in the game.

Whitton [61] demonstrated that adult learning theory has a lot in common with the constructivist approach to learning since it advocates learners taking responsibility for their learning and allows them to learn via experience in an authentic context. A constructivist approach was applied in the development of Investigate: Tudors, since learners could progressively construct their understanding of note-taking best practices and develop effective note-taking skills from actively interacting with the game. Constructivism is associated with active learning theory, which recognises learning as an active process [13], where learners build at the same time on past experiences and knowledge. Constructivism and active learning are particularly relevant to learning via digital games in higher education and it could be argued that certain types of games are constructivist learning environments [61]. Considering the pedagogic goals of constructivist learning environments [32], the design of Investigate: Tudors focused on making the practice of note-taking authentic and relevant via basing learning tasks on real life activities. The game also uses representation and rich media to allow learners to practice skills in this authentic context, and later transfer them to the real world. Determining the learning theory, which in turn informs the game design is important for GBL, since it frames the theoretical context of the work. Even more so since GBL studies often fail to address theoretical foundations or to use learning theories [44, 64], although research has shown that there are considerably positive outcomes when a learning theory is incorporated into the game's design [62].

Gee claims that learning principles are embedded in games [30], while Schell argues that games mimic education in that students (players) are given goals to accomplish in the form of assignments for which they receive feedback, until mastering the skills necessary to progress in the course (game) [53]. Parallels exist between learning and play, and games have potential as educational environments, especially via learning rich opportunities they create, which allow players to actively construct ideas and practice skills. The act of play in a computer game can facilitate the evolution of human experience in a safe environment, via opportunities to practice skills and explore behaviours that can then be transferred into everyday life [41]. Furthermore, games facilitate a sense of control which can motivate interaction, via allowing players to experience the effects of their own actions in the virtual game world [12]. They can also facilitate adaptivity and adaptability to foster different starting points and levels of experience and ability, which is key for the learning of adults. Finally, as learning is not only a conginite but also an emotional process, games have the potential to offer pleasurable experiences and to cultivate positive emotions that can impact the learning process [3].

\subsection{Game Genre and Subject Area}

Discussing digital GBL in HE, Whitton [61] identifies the educational potential of seven distinct game genres, emphasising the possibility of overlapping since individual games may fall into more than one category. The classification of game genres in the context of learning proposed by Whitton [61] includes Adventure, Platform, Puzzle, Role-play, Shooter, Sports and Strategy games. Looking at the genre characteristics and the learning potential of these types of games as described by Whitton [61], adventure and role-play were considered appropriate for Investigate: Tudors, due to their potential of providing contexts for problem solving where players undertake a series of tasks to achieve the objectives of the game via completing a quest, as well as providing opportunities for players to work through scenarios via adapting the role of a character in the game. The choice of genre is important in the design of GBL since it determines the kind of interactions the game will afford to players and helps establish conceptual constraints for the designers. In addition, the selected genres offered several tools for enabling learning that were appropriate for the learning objectives.

Gagné, Briggs \& Wager [29] identified five categories of learning which describe a range of skills, the development of which could be facilitated via games. Two of them are intellectual skills and cognitive strategies, which in the context of games could be facilitated via players finding solutions to problems through action, via using concepts and rules, an activity inherent to adventure games. Regarding the role-play genre, Prensky [51] discussed the relation between learning content and game styles, suggesting that games can be used to support a variety of different types of learning. Development of skills and judgement for instance, can be facilitated via storytelling, making choices, feedback, continuous practice and increasing challenge, often found in role-playing, detective and adventure games. Furthermore, the choice of a role-playing game as a successful design model for GBL, was supported by its potential to facilitate learning via an immersive environment in which players learn through role-playing experiences [57]. Talking about experiences created via games, Schell [53] argues that problem solving is embedded in gameplay and games provide opportunities to demonstrate ability to use skills in an integrated way to solve problems. Games like adventures require planning, strategy and decision-making in order to find solutions to problems in realistic situations simulated in the game world. Role-playing in games can create powerful learning opportunities via fostering new insights, since players can adopt the role of someone else via new realities with set rules that games create [53].

\subsection{Development Setting}

Investigate: Tudors was created by a team of five undergraduate games design students, supervised by a team of researchers. The game was developed under an annual student summer project, running in collaboration with a video games publishing studio. Twenty published games have been produced via the summer project so far, which is set up to help students get practical work experience in an industry where it is valuable to take an internship role. Students who take part in the project create games and see them through to publication, taking 
responsibility for every area of production throughout the entire development cycle.

The participation process mimics that of the industry. Each year students apply with a cover letter explaining whether they would like to undertake the role of producer, designer, programmer or artist. The producer is responsible for managing the team and making sure everything is on track and liaising with any external parties. In this instance, the producer was the main liaison between the student team, the researchers and key stakeholders such as members of the University's Academic Skills Service (ASK) team and members of the Disability and Dyslexia Service (DDS) team. Investigate: Tudors was developed in three months in a studio-based environment. The team of researchers supervising the development, visited the students daily to ensure the smooth development of the game, and to provide guidance and technical support. Students were also involved in design workshops aimed at developing the learning and design objectives of the game and experienced seeing firsthand the planning and development of a game-based learning project as well as how academic research is conducted.

\subsection{Game Specifications}

Investigate: Tudors was designed with accessibility and subject relevance in mind and the research team ran a series of consultations with the DDS and ASK to formulate design requirements. These consultations along with the development team's design workshops and subject research were the main instruments used to formulate design requirements before development began.

Players assume the role of a spy in Tudor times and are asked to play through a variety of missions across five different levels, where they have to use their note-taking skills. The key aim of the game is to unravel mysteries via listening in or being part of conversations in different scenaria and filling in spy reports at the end. To complete the reports, players need to take notes of important information during conversations. The writing of notes mechanic is there to increase cognitive effort and engagement and to ultimately add to learning [50]. Furthermore, encoding clues and making connections between new information and prior knowledge on the spy cases, facilitates comprehension and meaning [26]. A variety in gameplay via puzzle or strategy elements is incorporated into levels to facilitate engagement and variation. Different types of narrative have also been incorporated as spy cases to be resolved (from identifying suspect cases to heists), to further engage players and to enhance replayability value. Huang, Johnson, \& Han [33] proposed that game features such as animation, graphics and goals are key in engaging players and supporting learning, and such have been embedded in all levels of the game.

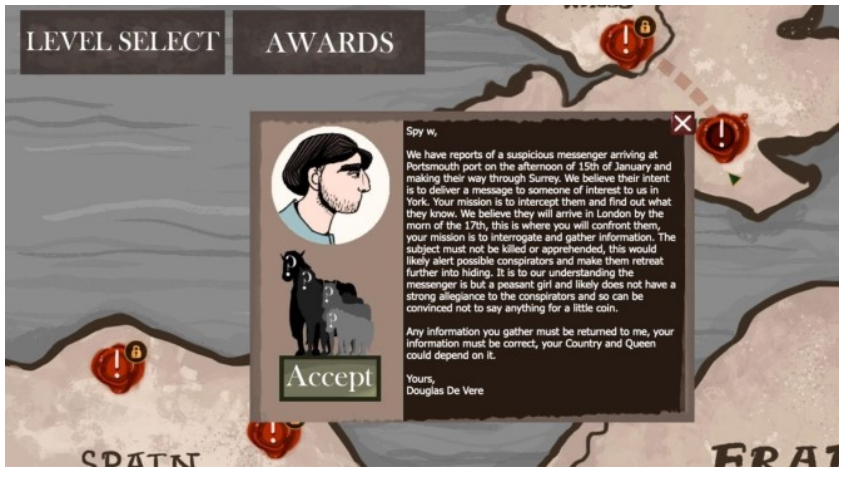

Figure 1: Game map and mission description.

The game allows for either a linear progression, where the levels are experienced sequentially, or a non-linear via level selection to test a specific note-taking skill. If players choose to play sequentially, they navigate through different levels via a game map (Fig. 1). Each level represents a mission. For each mission, players must solve different cases each one taking them through a scenario. New missions unlock as the game progresses, and players can read a short description before accepting the mission. If players opt for the non-linear format, they can choose the level they would like to play via a level selection screen (Fig.2). For each level, players can see the notetaking skills available to practice.

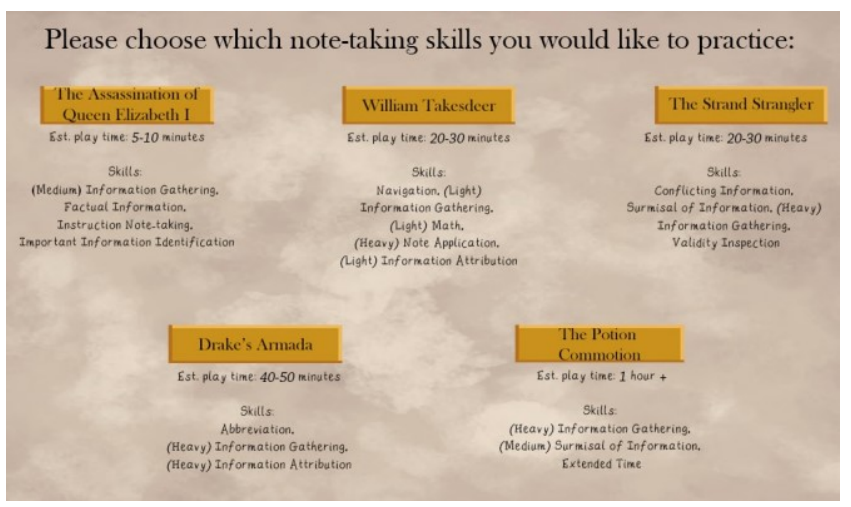

Figure 2: Level selection screen in non-linear format.

The game starts with an optional tutorial, which introduces gameplay and aims. During the tutorial, players get acquainted with the writing mechanic by being presented with information that they need to record in the form of notes. They are asked to complete a practice scenario and a short report. The tutorial introduces the core note taking process that is used in all levels (Fig. 3). The gameworld appears on the top window (1), the narrative unfolds via text on the bottom left box (2) and notes are being taken in the notepad on the bottom right box (3). 


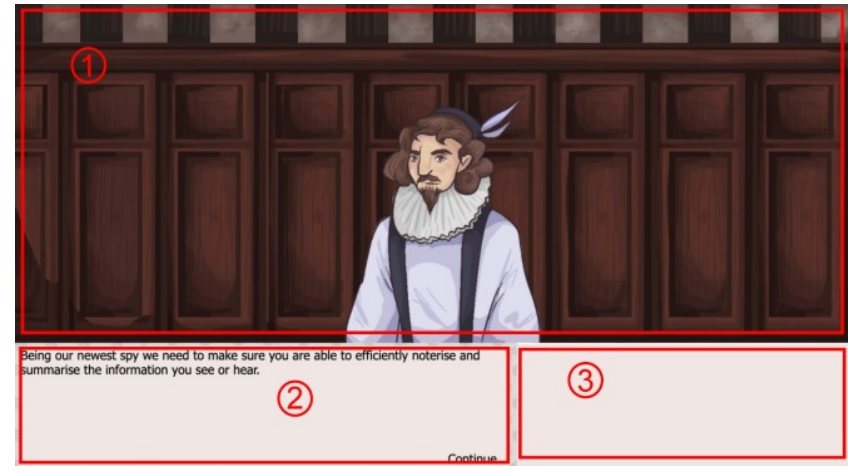

Figure 3: Game tutorial screen.

The tutorial is important for players to realise that their notes, taken throughout the scenario, will become available during the report completion phase and thus they should be clear and effectively summarise events. Although the note taking process is the same for all levels, the reports can take different formats depending on gameplay. The use of the tutorial enhances the learnability of the game system [25].

The game features five levels in total. The first level, "The Assassination of Queen Elizabeth I" is a mystery case where the player is tasked with saving the Queen from a bold attempt on her life, via identifying the details of a planned assassination. To do so, the player must interrogate a courier to gather information and prevent the treason. This level helps practice factual information gathering as well as important information identification. At the end of the level, the player revisits notes taken during the interrogation to fill in a spy report and solve the case. Fig.4 shows the report about the Queen's assassination, completed by dragging the word boxes into corresponding blank boxes. When ready to send the report, the player can click on the red seal stamp and the report will be checked. Correct answers are verified with a green tick and wrong ones are highlighted with a red cross, providing immediate visual feedback. This interactive puzzle mechanic encourages players to revisit and review their notes at the end of the level, helping them with knowledge association and retention [50]. The mechanic also considers interactivity via utilisation of notes rather than passive reading [7], a key factor associated with optimal review. Interactive review is here achieved via self-testing in the form of the spy report, drawing on Bjork [6] who showed that selftesting strengthens retrieval pathways and slows down the forgetting rate.

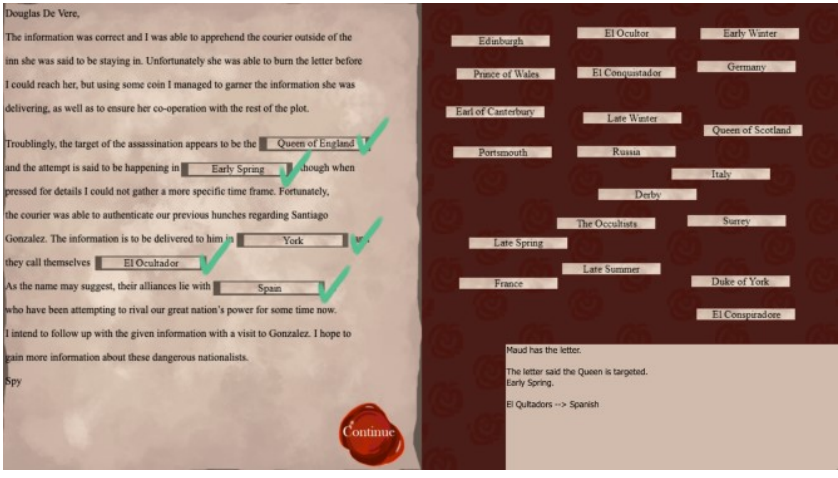

Figure 4: Spy report at the end of the case.

Finally, the mechanic facilitates early review, asking players to fill in the spy report at the end of each case, recognising that notes should be ideally reviewed shortly after creation rather than after a few days have passed [28].

Later game levels are longer, featuring more complex cases. A gradual increase in level difficulty is built into the game, aimed at making the player's initial interaction with the game comfortable (player on-boarding), via adding difficulty as familiarity with the system increases [23]. In the "William Takesdeer" level, the narrative revolves around a heist, where the player helps William Shakespeare get revenge by stealing a deer from an estate. Strategy elements like managing resources to hire a team to help the player succeed in the heist are incorporated into gameplay. The heist planning board can be seen in Fig.5. The player must use notes taken about each possible team member's abilities, introduced earlier in the mission, to help make the best possible choices. Skills like information gathering and attribution as well as note application can be practiced.

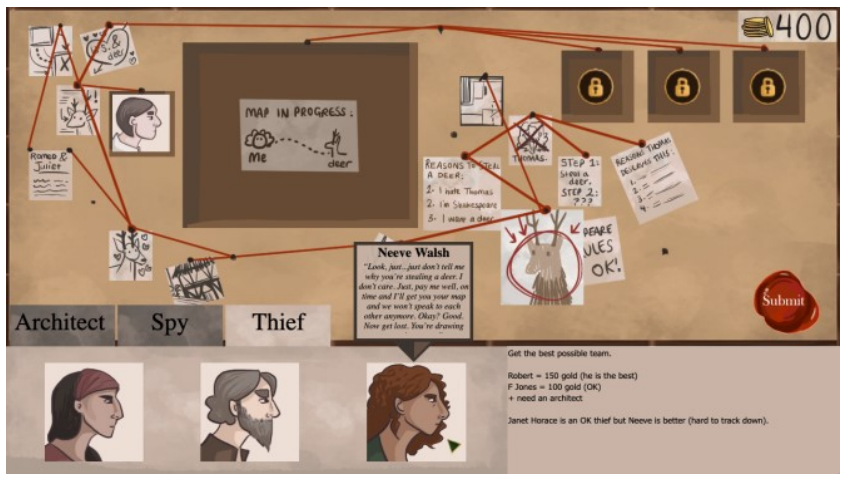

Figure 5: Heist planning board. 


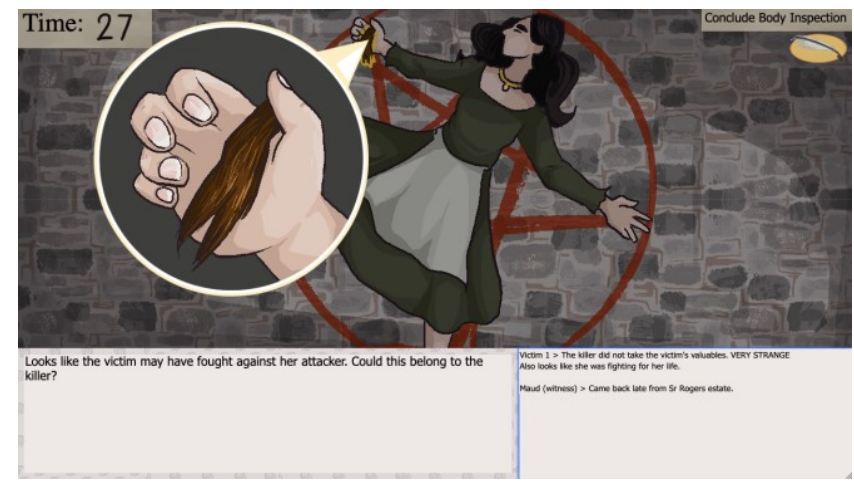

Figure 6: Crime scene investigation.

The "Strand Strangler" level is about bringing down a terrifying serial killer in a time without fingerprints and DNA evidence. The aim is to investigate five murders conducted in a short period of time and interrogate witnesses in order to collect useful notes to help identify the killer. Gameplay features crime scene inspections to gather further evidence from the victims (Fig.6). In this level skills like surmisal of information, information gathering and conflicting information as well as validity inspection can be practiced.

"Drake's Armada" is a naval officers level which utilises a strategy approach to gameplay. The player is tasked with developing the right strategy for battle against a foreign invasion to protect the country and the Queen. To successfully lead ships to battle, the player must learn about different battle tactics and ship formations. Information on possible generals, to best face opponents and lead to victory with minimal casualties, should also be gathered. Once all relevant information has been gathered in the form of player notes, players are asked to complete a battle report as seen in Fig.7. This level helps practice abbreviation, information gathering and attribution.

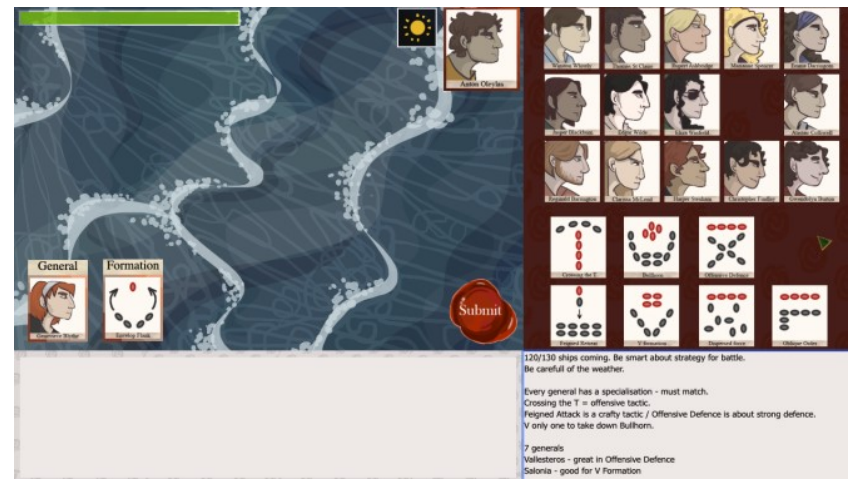

Figure 7: Battle planning report.

The "Potion Commotion" level features puzzle elements via alchemy and helps players practice heavy information gathering and surmisal of information over extended time. Here the player is first tutored in the art of potion making via noting down recipes as to how to mix different ingredients to create different types of potions (Fig.8).

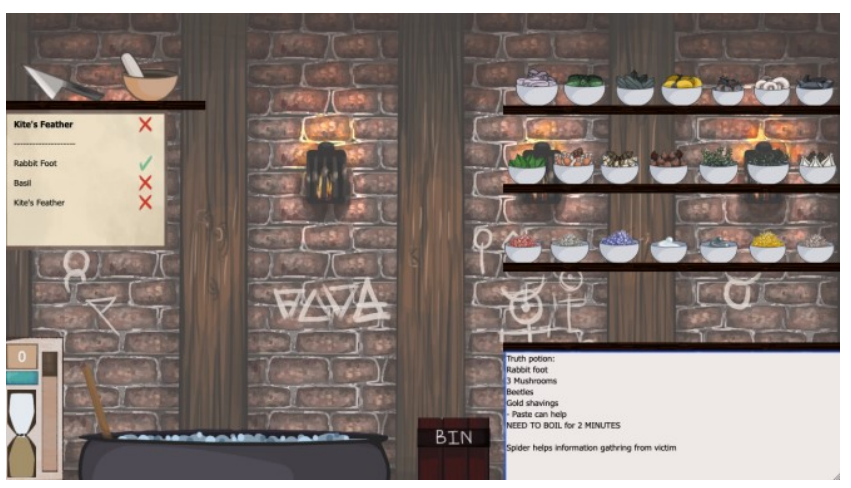

Figure 8: Potion making interface. Notes appear on the bottom right and recipe progress on the top left.

The most effective way to take notes to facilitate heavy information gathering in this level, is to avoid noting everything down, since overly wordy notes are unnecessary for potion recipes and will make it difficult for the player to go back and review specific content when needed. This mechanic draws on Friedman [28] who discusses how organised, coded and shorter notes reduce the burden on the note-taker's working memory and put the focus on comprehension.

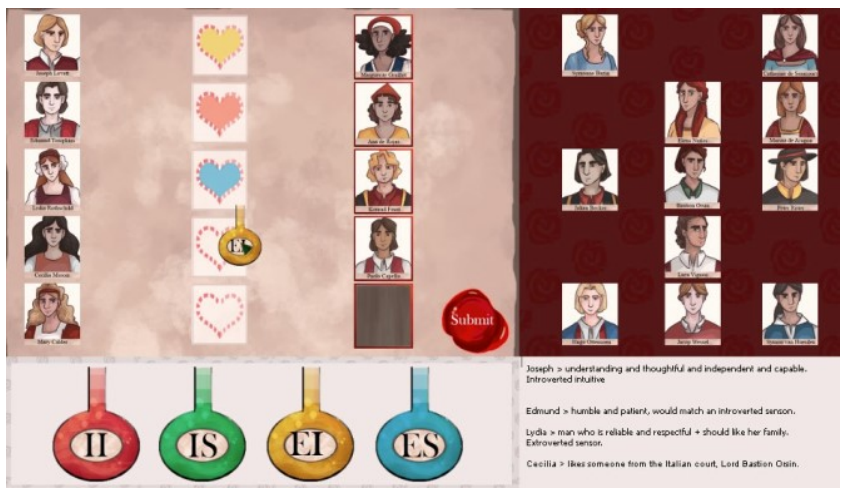

Figure 9: Matchmaking interface.

Puzzle elements and decision making are utilised in the later part of this level, where the player is tasked by the Queen to find suitable matches between lords and ladies of the court, to strengthen bonds between countries via marriage. The aim is to secure England's stability with alliances and lower threats of invasion. To create stronger matches, couples need to be formed based on personality types and via potions to further enhance the bonds. At the end of the level the player must fill in a 
matchmaking report (Fig.9), based on information gathered regarding individual wants and personalities.

Cues are provided throughout the game to emphasise the importance of the information provided [37]. As dialogue progresses during a scenario, such cues can be presented via repetition, use of pauses, or punctuation marks and there is also the use of a quill icon that only appears on the screen when the player should be taking notes, as a visual indication of important information being communicated (Fig. 10). The game features an awards system where players are rewarded based on their performance. This system provides a further incentive to do well and progress. King, Delfabbro \& Griffiths [38] found rewards and rare game items amongst the most enjoyable aspects of gameplay. Rewards are stored in an inventory in the form of trophies and can include prizes like a horse or a ship (Fig.11). As players progress, better rewards are unlocked.

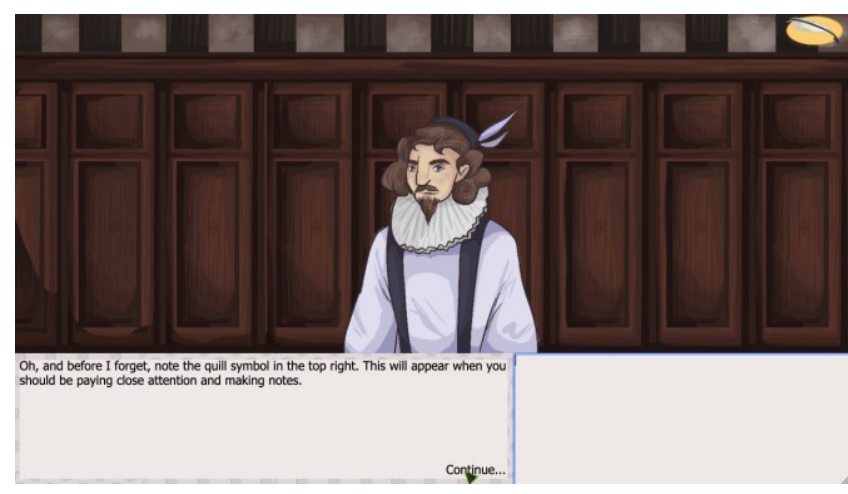

Figure 10: Quill icon indication during tutorial (top right).

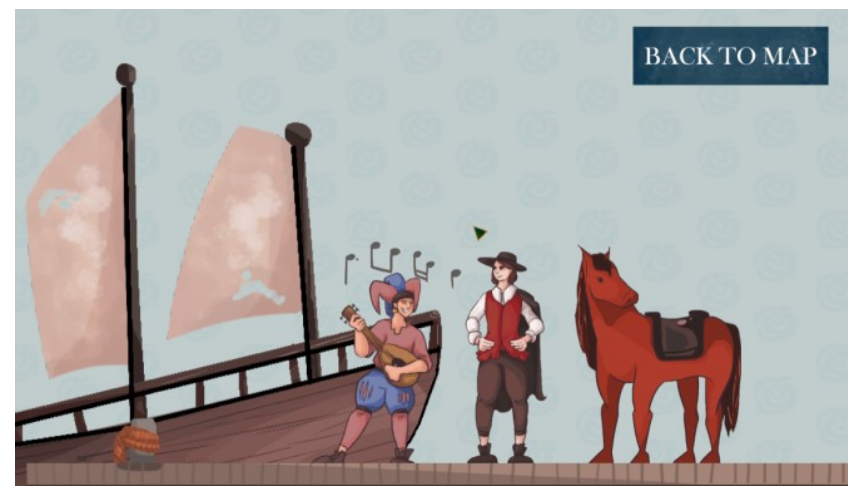

Figure 11: Awards inventory featuring rewards.

Mimicking distractions in real life lecture settings was another aim of the game design. To mimic distractions, animations were incorporated into some game screens in an attempt to distract the player when taking notes. An example can be seen in Fig.12, where a dog walks by the alley in the background while the suspect is talking. These allow players to practise not getting distracted, a skill which can then be carried forward into real lecture settings.

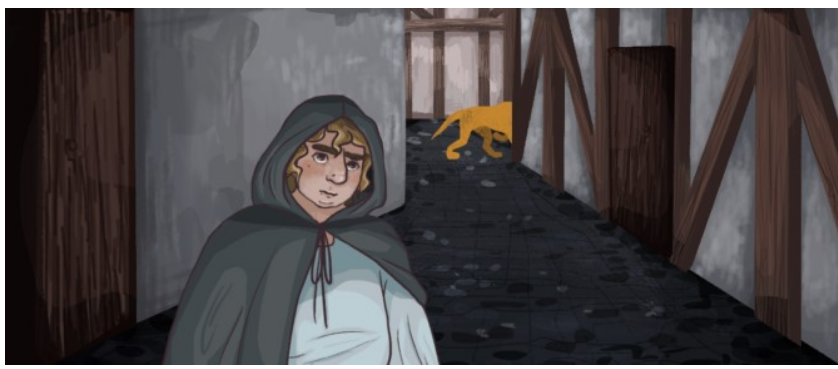

Figure 12: Distractions to mimic real life lecture settings.

Informed by microlearning design [16], Investigate: Tudors includes hints and tips on the loading screens, a time during which players are briefly idle. Microlearning is based on the idea of developing small chunks of learning content and presenting them in a series of microlearning units [34]. The hints and tips provided were informed by consultations with ASK advisors, as well as literature on effective note-taking practices. The hint shown on Fig.13 for example, 'Don't waste time writing information you have already written down or know, focus on new information', is informed by working memory capacity, which in the context of note-taking should be balanced between comprehension of information and production of notes, via identification of important and non-repeating content [28]. The hint thus prompts players to only write down new information to cultivate a habit of identifying key information instead of writing everything down which would make the note-taking practice merely a transcription event [45].

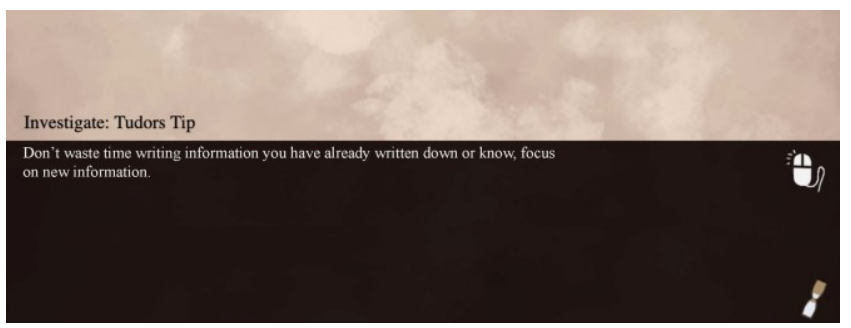

Figure 13: Example of hint provided on loading screen.

Finally, the game features a settings menu through which players can control the text scrolling speed, the font size of the notes box, and the game audio.

\section{Evaluation}

One of the key objectives of the study was to evaluate the effectiveness and engaging potential of Investigate: Tudors via playtesting with students once the development had been completed. Evaluation methods for educational games vary and 
often depend on context, since there is no one universal method of evaluating GBL [19]. Literature on GBL supports links between levels of engagement and learning [24, 43, 35, 61, 9, 17, 45]. By showing that an educational game is engaging, it could be inferred that skills development are facilitated and the overall learning design effectiveness is validated. It is also known that usable systems help maintain a seamless user experience and contribute to user engagement [5]. Based on this evidence, it was decided that the best approach for evaluating the game would be assessing engagement and usability, instead of employing a long-term skill development audit, which would be outside of the scope and timeframe of the project. The authors chose to conduct an evaluation at the end of the development cycle using questionnaires and focus group discussions that were driven by a set of playability and learning heuristics.

\subsection{Heuristic Evaluation for GBL}

Heuristic evaluation is an inspection technique where evaluators explore an interface using a set of usability principles, called heuristics. Heuristic evaluation is a method that is widely used in the field of Human-Computer Interaction (HCI) in order to determine the usability of a system. It is a very useful testing technique because it can be used early in the design process, even when the software is at an alpha prototype. There is not a set list of heuristics and evaluators can create their own list based on the intended software use. For example, research in HCI has produced a few sets of heuristics that are widely used for the design of software systems and services, such as Nielsen's [48] usability heuristics.

Video games, as software systems, can also benefit from this method. However, in terms of use, video games are different from standard software designed for productivity and, therefore, some of the heuristics are not applicable to games [27]. For example, Nielsen's heuristic of error prevention, which checks how prone a system is to errors, might be appropriate for a word processor, whereas in a game making mistakes is demanded as it forces players to develop new skills so that they can achieve ingame objectives [49]. This design philosophy is clear in Nolan Buschnell's quote: 'All the best games are easy to learn and difficult to master. They should reward the first quarter and the hundredth'. This level of challenge presupposes the space for errors on the side of the players. Making a system usable is always driven by the goals that the users of the system must achieve. If it is a word processor then usability testing will ensure that the user is able to carry all tasks related to typing and editing effortlessly. Games, on the other hand, are played for enjoyment and fun and playing games does not have a straightforward path of player actions that can be easily evaluated. Aspects of games such as gameplay, mechanics, hardware devices, and, importantly for GBL, learning content are areas that need to be additionally evaluated, as they are important to the playing experience.

In literature there is no set of learning heuristics for GBL applications. Zaibon \& Shiratuddin [66] have explored heuristics for evaluating the educational value of a mobile game, however their proposed heuristics are not based on any learning theory. These are:

LC1. The content can be learned easily

LC2. The game provides learning content

LC3. The learning objective from the game is achieved

LC4. The content is understandable

Arguably, LC1 is not a heuristic appropriate for an educational game as 'easiness' is not necessarily a prerequisite for learning. Games can trigger learning through mechanics that should require skill development and not be easy to master for the game to be engaging. To connect this with literature findings that when players are engaged they learn $[43,35]$, it is possible that the more engaged the players are in difficult situations requiring skills development the more engaged they are with learning. LC2 is a useful heuristic with the adjustment that the game provides learning content relevant to the learning outcomes. In addition, the learning materials should be provided during gameplay so that players have a resource to learn from. Therefore, the research team added a heuristic to test against the game providing the learning material, the resource from which the learning content is derived, in a clear and accessible way. LC3 is also a useful heuristic, however the authors do not provide any evaluation method for it. Based on the literature that correlates engagement with learning, evaluating whether a learning objective is achieved can be done by looking at the level of player engagement. Therefore, the following heuristic is proposed: The learner is engaged in the learning activity. Finally, LC4, whether the content is understandable, is an issue related to usability and not to learning. The proposed learning heuristics then that drove the Investigate: Tudors evaluation based on learning theories, are:

L1. The game provides the learning material in a clear and accessible way

L2. The learning content is relevant to the learning outcomes

L3. The learner is engaged in the learning activity

These heuristics were addressed through the questionnaires and the focus group discussions as shown in the next section.

\subsection{Playtesting the Game}

A playtesting session was organised, during which 13 users were asked to play the game freely for an hour. These users were students of HE, three at undergraduate and ten at postgraduate level. The participants were recruited via a playtesting call, word of mouth and through the researchers' networks. Data gathering focused on a qualitative research method and during the playtest, participants were observed and then asked to complete a questionnaire about their experience using a 1-5 (strongly disagree-strongly agree) Lickert scale. Feedback was also gathered verbally after the playtest in a debriefing activity during which participants were invited to discuss their experience playing the game in a focus group. The questions 
used in the survey (Appendix A.1) were informed by Whitton's questionnaire to measure post- experiential engagement with educational games [61] and crafted with respect to the identified learning heuristics. For example, questions 1,3,5,10 and 11 of the survey (A.1) addressed L1, question 4 and 9 addressed L2, and questions 2,6,7 and 8 addressed L3. The focus groups questions (Appendix A.2) were more open-ended but aimed at providing in depth responses to the identified heuristics, for example by asking directly if playing the game was engaging and the reasons for their response as a dialogue starting question.

\section{Discussion}

The game was successful in engaging cognitively and emotionally the players in all aspects of note-taking. We discuss below results and observations under each learning heuristic.

\subsection{The game provides the learning material in a clear and accessible way (L1)}

$100 \%$ of participants agreed that it was clear what they could learn from the game. A $92.3 \%$ found it easy to get started, and only a $15.4 \%$ could not tell what effects their actions had in the game. Participants also commented positively on the incremental introduction to note-taking starting with simple information gathering and moving to explore the other aspects, often their combination, through gameplay of increased difficulty.

One point that was raised was the 'red herring' answers to the input questions. A lot of the words that players had to choose resembled the words that they should have taken down as notes. However, in the case of students with spelling difficulties or dyslexia this represents a disproportionate level of difficulty to what the game intends to offer. The game design should take this particular characteristic of this group of players into account and offer different strictness modes or difficulty levels.

Moreover, a few participants suggested the use of voice over for the characters. Voice over is an additional modality useful for a large group of players and will also animate the characters and make the game more engaging.

\subsection{The learning content is relevant to the learning outcomes (L2)}

L2 was also met successfully. Focus group discussion showed that about $65 \%$ of the participants agreed that the game would help them develop their note-taking skills with some observing that younger learners could use it as well. $46.2 \%$ of participants agreed that they would see themselves using the game to develop their note taking skills with $38.5 \%$ giving a neutral response (neither agree nor disagree). Focus group discussions revealed that the reason behind the neutral responses was that those students were already very good at note-taking so they wouldn't play the game again. This correlates with the $30.8 \%$ in the survey results who agreed that they would not play the game again. However, the consensus among all participants was that they found it a good tool to keep up the skill.
Furthermore, participants found particularly useful the fact that the different missions of the game offered a practice ground for the different aspects of note taking, such as information gathering and organising, information attribution, abbreviation, surmisal of information, and conflicting information. This further enforces L2 and also validates the importance of the design approach that was followed: using the findings of preliminary research on note-taking in $\mathrm{HE}$ to inform game mechanics that address the skillset holistically. Arguably, this observation may lead to introducing a new learning heuristic related to whether players become aware of or recognize the educational content and the buildup of their experience. It is worth noting that learning heuristics for games is an underresearched field and there is a need for further empirical research to extend our knowledge on it.

\subsection{The learner is engaged in the learning activity (L3)}

$90 \%$ of the participants found the game engaging. $92.3 \%$ found it easy to get started while $53.9 \%$ was interested to explore all the available scenarios and indicated that they were absorbed in the activity. $46.2 \%$ felt that time passed quickly which is a measure of engagement with the game through immersion. Engagement with the game could also be demonstrated via observations since $89 \%$ of play testers used up the full hour assigned to the playtesting phase of the evaluation without deviating from the activity, while $63 \%$ requested to keep playing the game for longer.

Azita et al [2] who investigated game design features that promote engagement and learning in GBL settings, suggested that motivational, interactive, fun and multimedia elements in a game create opportunities for emotional and cognitive engagement in gameplay. The evaluation showed that Investigate: Tudors included all these four elements. In terms of motivation it included clear and diverse objectives, rules, and a ranking element with rewards for successful completion of objectives. The playtests showed that the players found it deeply motivating striving to succeed in every different objective they were presented with. They also deemed as rewarding the fact that they were able to progress through a variety of mission stories and types of gameplay in different levels. The differentiation in the puzzles and narratives offered also amble interaction points with diverse characters, and opportunities for role-play. Azita [2] mentions all these as aspects of the fun element.

All participants commented on the attractiveness and appropriateness of the visual art style, and its fit with the Tudor era, particularly the design of the characters, which helped them further immerse in the historic period. Also positive was the humorous atmosphere of the game. In the discussions the majority of participants commented positively on the music and use of environmental sound effects commenting that the music fitted the theme and was a nice backdrop. They also mentioned the effectiveness of the interface animations suggesting the inclusion of more of these in the game. This feedback, with the 
comment on adding voice over, enforces the success of the game in engaging the players based on Azita's multimedia element [2]. Most participants except one found that the distractions worked very well and mimicked realistically the real world distractions.

\section{Conclusions}

Investigate: Tudors has been designed as a standalone learning game, which HE students can use to develop and practice notetaking skills. The design of the game mechanics was directly informed by a constructivist learning approach and considered the characteristics of $\mathrm{HE}$ students as adult learners. It also considered a game genre suitable for the type of learning and aligned the game objectives with the learning outcomes.

The evaluation showed that the game design approach was appropriate for creating an engaging game through which students could effectively practice a wide range of note-taking skills. It is therefore considered that the findings and the proposed learning heuristics, contribute to good practice strategies for designing similar games. Such design practice strategies could be used for designing educational games for note-taking skills or applied to different contexts. These insights are presented here as the basis for future research or applications in the area.

An important observation is the strength of having an interdisciplinary team leading the development. The Investigate: Tudors design team included game designers, game-based learning experts, academic skills development experts, accessibility consultants, and human-computer interaction designers. Interdisciplinary collaboration is a key factor in fusing learning theories with game design effectively.

\section{ACKNOWLEDGMENTS}

This research was supported by Brunel University's Student Success Project initiative. The authors would like to thank Professor Mariann Rand-Weaver and Robyn Fitzharris for their guidance and support and the game design students who developed the game, Harry Prebble, Sam Pickard, Olivia Jeremiah, Phill Shaw and Reece Merryweather-Brown. The authors would also like to thank Jason Hamer from Octopus 8 studios for their ongoing support.

\section{REFERENCES}

[1] Miguel de Aguilera and Alfonso Mendiz. 2003. Video games and education: (Education in the Face of a "Parallel School"). Comput. Entertain. 1, 1, Article 1 (October 2003), 10 pages. DOI: https://doi.org/10.1145/950566.950583

[2] Ilia Azita, Abdul Jabbar and Felicia Patrick. 2015. Gameplay Engagement and Learning in Game-Based Learning: A Systematic Review. Review of Educational Research 85, no. 4 (December 2015): 740-79. DOI: http://doi.org/10.3102/0034654315577210.

[3] Ryan S.J.D Baker, Sidney K. D'Mello, MA. Mercedes T. Rodrigo, and Arthur C. Graesser. 2010. Better to be frustrated than bored: The incidence, persistence, and impact of learners' cognitive- affective states during interactions with three different computer-based learning environments. International fournal of Human-Computer Studies, 68, 4: 223-241

[4] Julia Bennett and Danielle McKain. "The iPad: A Mobile Learning Device and Innovative Note-Taking Tool." In Handbook of Research on Mobile Devices and Smart Gadgets in K-12 Education, ed. Amar Ali Khan and Sajid Umair, 194-224 (2018), accessed April 18, 2020. DOI:10.4018/978-1-5225-2706-0.ch013

[5] David Benyon. 2014. Designing Interactive Systems: A comprehensive guide to $\mathrm{HCI}$ and interaction design. Addison Wesley.
[6] Robert A. Bjork. 1975. Retrieval as a Memory Modifier: An interpretation of negative regency \& related phenomena. Information Processing and Cognition: The Loyola Symposium.

[7] Robert A. Bjork, John Dunlosky, and Nate Kornell. 2013. Self-Regulated Learning: Beliefs, Techniques, and Illusions. Annual Review of Psychology 64, no. 1 (March 2013): 417-44. DOI: https://doi.org/10.1146/annurev-psych113011-143823.

[8] Donald A. Bligh. 2000. What's the use of lectures? San Francisco, CA: JosseyBass.

[9] Patrice Bouvier, Elise Lavoué, Karim Sehaba and Sébastien George. 2013 Identifying Learner's Engagement in Learning Games: a Qualitative Approach based on Learner's Traces of Interaction. CSEDU 2013 - Proceedings of the 5th International Conference on Computer Supported Education. DOI: https://doi.org/10.5220/0004386903390350.

[10] Elizabeth A. Boyle, Thomas M. Connolly, and Thomas Hainey. 2011. The Role of Psychology in Understanding the Impact of Computer Games. Entertainment Computing 2, no. 2 (2011): 69-74. DOI https://doi.org/10.1016/j.entcom.2010.12.002.

[11] Elizabeth A. Boyle, Thomas Hainey, Thomas M. Connolly, Grant Gray, Jeffrey Earp, Michela Ott, Theodore Lim, Manuel Ninaus, Claudia Ribeiro, and João Pereira. 2016. An Update to the Systematic Literature Review of Empirical Evidence of the Impacts and Outcomes of Computer Games and Serious Games." Computers \& Education 94 (2016): 178-92. DOI : https://doi.org/10.1016/j.compedu.2015.11.003.

[12] Johannes Breuer, Gary Bente. 2010. Why so serious? On the relation of serious games and learning. Fournal for Computer Game Culture 4, 1: 7-24

[13] Jerome S. Bruner. 1966. Toward a Theory of Instruction. Oxford: Oxford University Press.

[14] Peter Brandl, Christoph Richter, and Michael Haller. 2010. NiCEBook. In Proceedings of the 28th international conference on Human factors in computing systems - CHI 10, 599-608. DOI: http://doi.org/10.1145/1753326.1753417

[15] Gayle A. Brazeau. 2006. Handouts in the Classroom: Is Note Taking a Lost Skill? American fournal of Pharmaceutical Education 70, 2: 38 . DOI: http://doi.org/10.5688/aj700238

[16] Jian Chen, Yueqin Zhang, Jingyu Sun, Yongle Chen, Fuping Lin, and Qun Jin. 2015. Personalized Micro-Learning Support Based on Process Mining. 2015 7th International Conference on Information Technology in Medicine and Education (ITME). DOI: http://doi.org/10.1109/itme.2015.120

[17] Douglas B. Clark, Emily E. Tanner-Smith and Stephen S. Killingsworth. 2016. Digital Games, Design, and Learning: A Systematic Review and MetaAnalysis. Review of Educational Research 86, no. 1 (March 2016): 79-122. DOI: http://10.3102/0034654315582065.

[18] Thomas M. Connolly, Elizabeth A. Boyle, Ewan Macarthur, Thomas Hainey, and James M. Boyle. 2012. A systematic literature review of empirical evidence on computer games and serious games. Computers \& Education 59, 2: 661-686. DOI: http://doi.org/10.1016/j.compedu.2012.03.004

[19] Thomas Connolly, Mark Stansfield, and Thomas Hainey. 2009. Towards the Development of a Games-Based Learning Evaluation Framework. Games Based Learning Advancements for Multi-Sensory Human Computer Interfaces: 251-273. DOI: http://doi.org/10.4018/978-1-60566-360-9.ch015

[20] Francesco Crocco, Kathleen Offenholley, and Carlos Hernandez. 2016. A Proofof-Concept Study of Game-Based Learning in Higher Education. Simulation \& Gaming 47, 4: 403-422. DOI: http://doi.org/10.1177/1046878116632484

[21] Mihaly Csikszentmihalyi. 2009. Flow: the psychology of optimal experience Harper Row, New York

[22] Sara I. De Freitas. 2006. Using games and simulations for supporting learning. Learning, Media and Technology 31, 4: 343-358. DOI http://doi.org/10.1080/17439880601021967

[23] Thaleia Deniozou. 2016. Investigating the potential of mobile games as learning environments for independent adult skill development. Doctoral Dissertation, http://hdl.handle.net/1842/22926. Accessed 1st February 2020.

[24] Michele D. Dickey. 2005. Engaging by design: How engagement strategies in popular computer and video games can inform instructional design. Educational Technology Research and Development 53, 2: 67-83. DOI http://doi.org/10.1007/bf02504866

[25] George Skaff. Elias, Richard Garfield, and Karl Robert Gutschera. 2012 Characteristics of games. MIT Press, Cambridge, MA.

[26] Jean E. Faber, John D. Morris, Mary G. Liberman. 2000. The Effect of Note Taking on Ninth Grade Students Comprehension. Reading Psychology 21, 3: 257-270. DOI: http://doi.org/10.1080/02702710050144377

[27] Melissa A. Federoff. 2002. Heuristics and Usability Guidelines for the Creation and Evaluation of Fun in Video Games. Indiana University Master of Science Thesis.

[28] Michael C. Friedman. 2014. Notes on Note-Taking: Review of Research and Insights for Students and Instructors, Harvard Initiative for Learning and Teaching, Harvard University, online report available at https://hwpi.harvard.edu/hilt/files/hilt/files/notetaking_0.pdf, accessed 3rd March 2020 
[29] Robert M. Gagne, Leslie J. Briggs, and Walter W. Wager. 1974. Principles of instructional design. Rinehart and Winston.

[30] James Paul. Gee. 2007. What video games have to teach us about learning and literacy. Palgrave Macmillan, London.

[31] Peter Hodson, Michael Connolly, and Danny Saunders. 2001. Can Computerbased Learning Support Adult Learners? Journal of Further and Higher Education 25, 3: 325-335. DOI: http://doi.org/10.1080/03098770120077685

[32] Peter C. Honebein. 1996. Seven goals for the design of constructivist learning environments. Constructivist learning environments: Case Studies in Instructional Design, 11-24.

[33] Wenhao David Huang, Tristan E. Johnson, and Seung-Hyun Caleb Han. 2013. Impact of online instructional game features on college students' perceived motivational support and cognitive investment: A structural equation modeling study. The Internet and Higher Education 17: 58-68. DOI : http://doi.org/10.1016/j.iheduc.2012.11.004

[34] Theo Hug, Manfred Lindner and Peter A. Bruck. 2006. Microlearning: Emerging Concepts, Practices and Technologies after e-Learning. Proceedings of Microlearning: Learning \& Working in New Media. Innsbruck University Press.

[35] Richard Jacques, Jenny Preece, and Tom Carey. 1995. Engagement as a Design Concept for Multimedia. Canadian Journal of Learning and Technology / La revue canadienne de l'apprentissage et de la technologie 24, 1. 49-59. DOI : http://doi.org/10.21432/t2vg77

[36] Kenneth A. Kiewra. 1989. A review of note-taking: The encoding-storage paradigm and beyond. Educational Psychology Review 1, 2: 147-172. DOI: http://doi.org/10.1007/bf01326640

[37] Kenneth A. Kiewra, Tiphaine Colliot and Junrong Lu. 2018. Note this: How to improve student note taking. IDEA Paper \#73. The IDEA Center. http://www.ideaedu.org, Accessed 23 February 2020.

[38] Daniel L. King, Paul H. Delfabbro, and Mark D. Griffiths. 2010. The Role of Structural Characteristics in Problematic Video Game Play: An Empirical Study. International fournal of Mental Health and Addiction 9, 3: 320-333. DOI: http://doi.org/10.1007/s11469-010-9289-y

[39] Malcolm S. Knowles. 1998. The adult learner: the definitive classic in adult education and human resource development: 5 th ed. Butterworth-Heinemann, Woburn, MA.

[40] Keiichi Kobayashi. 2006. Combined Effects of Note-Taking/-Reviewing on Learning and the Enhancement through Interventions: A meta-analytic review. Educational Psychology 26, 3: 459-477. DOI: http://doi.org/10.1080/01443410500342070

[41] Raph Koster. 2004. A Theory of Fun for Game Design. Scottsdale, AZ: Paraglyph Press, Inc.

[42] Petros Lameras, Sylvester Arnab, Ian Dunwell, Craig Stewart, Samantha Clarke, and Panagiotis Petridis. 2016. Essential features of serious games design in higher education: Linking learning attributes to game mechanics. British fournal of Educational Technology 48, 4: 972-994. DOI: http://doi.org/10.1111/bjet.12467

[43] Mark Lepper and Thomas W. Malone. 1987. Intrinsic motivation and instructional effectiveness in computer-based education. In R. Snow and M. Farr (Eds), Aptitude, Learning and Instruction, vol. 3: Cognitive and Affective Process Analysis. Hillside, NJ: Lawrence Erlbaum Associates.

[44] Ming-Chaun Li and Chin-Chung Tsai. 2013. Game-Based Learning in Science Education: A Review of Relevant Research. Fournal of Science Education and Technology 22, 6: 877-898. DOI: http://doi.org/10.1007/s10956-013-9436-x

[45] Karen Markey and Chris Leeder. 2011. Students' Behaviour Playing an Online Information Literacy Game. Journal of Information Literacy 5, 2, 46-65. DOI: http://doi.org/10.11645/5.2.1637

[46] Marmalade Game Studio Ltd. 2018. Clue/Cluedo: The Classic Mystery Game. Game [PC]. (17 May 2018). Marmalade Game Studio Ltd., London, UK.

[47] Pam A. Mueller and Daniel M. Oppenheimer. 2018. Corrigendum: The Pen Is Mightier Than the Keyboard: Advantages of Longhand Over Laptop Note Taking. Psychological Science 25, 6, 1159-1168. DOI: http:// doi.org/10.1177/0956797614524581

[48] Jakob Nielsen. 2009. Usability engineering. Morgan Kaufmann, Amsterdam.

[49] David Pinelle and Nelson Wong. 2008. Heuristic evaluation for games. In Proceedings of the twenty-sixth annual CHI conference on Human factors in computing systems - CHI $08 . \quad 1453-1462$, DOI: http:// doi.org/10.1145/1357054.1357282

[50] Annie Piolat, Thierry Olive, and Ronald T. Kellogg. 2005. Cognitive effort during note taking. Applied Cognitive Psychology 19, 3: 291-312. DOI: http://doi.org/10.1002/acp.1086

[51] Marc Prensky. 2007. Digital game-based learning. Paragon House, St. Paul, Minn.

[52] Meihua Qian and Karen R. Clark. 2016. Game-based Learning and 21st century skills: A review of recent research. Computers in Human Behavior 63: 50-68. DOI: http://doi.org/10.1016/j.chb.2016.05.023

[53] Jesse Schell. 2008. The art of game design: a book of lenses. Morgan Kaufmann Publishers Inc., USA
[54] Kurt Squire. 2011. Video games and learning: teaching and participatory culture in the digital age. Teachers College, New York, NY.

[55] Elizabeth Moore Stacy and Jeff Cain. 2015. Note-taking and Handouts in The Digital Age. American fournal of Pharmaceutical Education 79, 7: 107. DOI: http://doi.org/10.5688/ajpe797107

[56] Team Bondi. 2011. L.A. Noire.. Game [PC, PS3, PS4]. (17 May 2011). Rockstar Games, NY, US.

[57] Peter Twining. 2010. Virtual worlds and education. Educational Research, 52, 2, 117-122. DOI: https://doi.org/10.1080/00131881.2010.482730

[58] T. Valtonen, S. Havu-Nuutinen, P. Dillon, and M. Vesisenaho. 2011. Facilitating collaboration in lecture-based learning through shared notes using wireless technologies. Journal of Computer Assisted Learning 27, 6: 575-586. DOI: http://doi.org/10.1111/j.1365-2729.2011.00420.x

[59] Jacques Van Der Meer. 2012. Students' note-taking challenges in the twentyfirst century: considerations for teachers and academic staff developers. Teaching in Higher Education 17, 1: 13-23. DOI: http://doi.org/10.1080/13562517.2011.590974

[60] Paul Weener. 1974. Note taking and student verbalization as instrumental learning activities. Instructional Science 3, 1: 51-73. DOI: http://doi.org/10.1007/bf00117026

[61] Nicola Whitton. 2010. Learning with digital games: a practical guide to engaging students in higher education. Routledge, New York.

[62] Wen-Hsiung Wu, Wen-Bin Chiou, Hao-Yun Kao, Chung-Hsing Alex Hu, and Sih-Han Huang. 2012. Re-exploring game-assisted learning research: The perspective of learning theoretical bases. Computers \& Education 59, 4: 11531161. DOI:http://doi.org/10.1016/j.compedu.2012.05.003

[63] Ya-Ting C. Yang and Wan-Chi I. Wu. 2012. Digital storytelling for enhancing student academic achievement, critical thinking, and learning motivation: A year-long experimental study. Computers \& Education 59, 2: 339-352. DOI: http://doi.org/10.1016/j.compedu.2011.12.012

[64] Michael F. Young, Stephen Slota, Andrew B. Cutter, et al. 2012. Our Princess Is in Another Castle. Review of Educational Research 82, 1: 61-89. DOI: http://doi.org/10.3102/0034654312436980

[65] Mark R. Young. 2016. Knowledge Acquisition and Readiness Assurance Testing: The Connected Notes Intervention. Fournal of Marketing Education 38, 3: 145-156. DOI: http://doi.org/10.1177/0273475316639630

[66] Syamsul Bahrin Zaibon and Norshuhada Shiratuddin. 2010. Heuristics Evaluation Strategy for Mobile Game-Based Learning. 2010 6th IEEE International Conference on Wireless, Mobile, and Ubiquitous Technologies in Education, 127-131. DOI: http://doi.org/10.1109/wmute.2010.27

\section{A QUESTIONS USED}

\section{A.1. Survey Questions}

The following questions were used for the survey conducted with the playtest participants.

1. I found it easy to get started.

2. I enjoyed the game.

3. It was clear what I could learn from the game.

4. I would see myself using the game to develop my notetaking skills.

5. I could not tell what effects my actions had in the game.

6. I felt that time passed quickly.

7. I was not interested in exploring the options available.

8. I felt absorbed in the activity.

9. I would play the game again.

10. The hints in the loading screens were helpful.

11. The report section was useful. 


\section{A.2. Playtest Questions}

The following questions were used for the focus group conducted with the playtest participants.

1. Tell us about your experience playing the game. How did it feel?

2. Was there anything that you particularly liked/disliked?

3. Do you think that using the game for a longer period of time would help you with note taking skills?

Why/Why not?
4. Was the activity you undertook engaging? Why/Why not?

5. Do you think a game like this would be suitable to help students develop note-taking skills?

6. How would you like to see this game develop? Any suggestions? 